\title{
Quality of supportive care for patients with advanced lung cancer in the Veterans Health Administration
}

\author{
Sabine M Oishi, PhD, MSPH, ${ }^{a}$ Anna Liza M Antonio, MS, ${ }^{a, b}$ Joan Ryoo, MD, MSHS, ${ }^{c}$ \\ Diana L Ordin, MD, MPH, ${ }^{d}$ Karl A Lorenz, MD, MSHS, ${ }^{a}$ Ren He, PhD, MA, ${ }^{\mathrm{b}}$ Steven M \\ Asch, MD, MPH, ${ }^{\mathrm{e}, \mathrm{f}}$ Benjamin Kim, MD, MPhil, ${ }^{\mathrm{g}}$ and Jennifer Malin, MD, PhD, ${ }^{\mathrm{a}, \mathrm{h}}$
}

${ }^{\mathrm{a}}$ Veterans Administration Greater Los Angeles Healthcare System; ${ }^{b}$ Fielding School of Public Health, Department of Biostatistics, University of California, Los Angeles; 'Department of Radiation Oncology, Kaiser Permanente Los Angeles Medical Center; ${ }^{\mathrm{d} O f f i c e}$ of Informatics and Analytics, Veterans Health Administration, Washington DC; ${ }^{e}$ Veterans Administration Palo Alto Health Care System, California; ${ }^{\mathrm{f} D i v i s i o n}$ of General Medical Disciplines, Stanford University, California; ${ }^{\mathrm{g} D i v i s i o n}$ of Hematology/Oncology, Department of Medicine, University of California, San Francisco; ' $\mathrm{H}$ Jonsson Comprehensive Cancer Center, University of California, Los Angeles

Background Morbidity related to cancer and its treatment remains a significant source of human suffering and a challenge to the delivery of high-quality care.

Objective To develop and apply quality indicators to evaluate quality of supportive care for advanced lung cancer in the Veterans Health Administration (VHA) and examine facility-level predictors of quality.

Methods We evaluated supportive care quality using 12 quality indicators. Data were taken from VHA electronic health records for incident lung cancer cases occurring during 2007. Organizational characteristics of 111 VHA facilities were examined for association with receipt of care.

Results Rates of care-receipt were high, especially in the treatment toxicity $(89 \%)$ and pain management $(79 \%-98 \%)$ domains, but were lower in the palliative cancer treatment $(60 \%-90 \%)$ and hospice $(75 \%)$ domains, with substantial facility- level variation. Presence of a care tracking method that was monitored by a midlevel practitioner seemed to be associated with better quality for treatment toxicity $(O R, 3.38$; $95 \% \mathrm{Cl}, 1.87-6.10)$ and referral to hospice (OR, 1.60; 95\% Cl, 1.22-2.28); having a psychologist for cancer patients was associated with higher odds for pain management (OR, 1.76; $95 \% \mathrm{Cl}, 1.16-2.66)$.

Limitations Not all supportive care was evaluated. Care processes identified as present at facilities may not have been applied to cohort patients. Facility-level results may be influenced by errors in attributing a patient's care to the correct facility.

Conclusions Quality indicators for supportive cancer care can be developed and applied in large evaluations using electronic health record review. This study confirmed high-quality supportive care, while identifying significant facility-level variation in VHA.

Funding Veterans Health Administration Office of Informatics and Analytics.

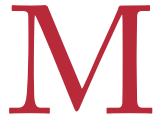
orbidity related to cancer and its treatment remains a significant source of human suffering and a national challenge to delivery of high quality cancer care. Quality care refers to the delivery of state-of-the-art treatments intended to achieve cure or prolong life as well as the supportive processes that address the diseaseand treatment-related burdens of living with cancer. These processes span the cancer care continuum from diagnosis to end of life, and include pain-, symptom-, and side effect- management; psychosocial support; communication needs; and support for caregivers. ${ }^{1-5}$
A 2006 report from the Agency for Healthcare Research and Quality concluded that "a large number of measures are available for addressing palliative cancer care, but testing them in relevant populations is urgently needed." ${ }^{\prime}$ Since then, evidence-based standards have been translated into "quality indicators" that may be used to identify outcome targets indicative of quality care, such as patient reports of pain reduction; or, they may specify facility-level care processes associated with these outcomes, such as pain screening, treatment, and follow-up assessment. ${ }^{1,79}$ Quality indicators can be used as the basis

Accepted for publication February 24, 2014. Correspondence: Sabine Oishi, PhD, MSPH; sabine.oishi@va.gov. Disclosures: Dr Ryoo was supported in part by the Robert Wood Johnson Foundation Clinical Scholars Program and by the UCLA Jonsson Comprehensive Cancer Center R25 grant. The authors have no direct conflicts of interest to disclose. Dr Karl Lorenz is a consultant as a member of the Data Monitoring Committee for a Phase II trial of Sativex being conducted by Otsuka Pharmaceuticals. The current study has no direct financial implications related to his participation and was conducted entirely outside of the timeframe of his consultancy; however, it may be perceived as indirectly related. The views and opinions of authors expressed herein do not necessarily state or reflect that of the Department of Veterans Affairs, the United States Government, Kaiser Permanente, Stanford University, or the University of California. JCSO 2014;12:361-369. (C)2014 Frontline Medical Communications. DOI 10.12788/jcso.0079. 
for tools to measure processes that are critical to ensuring high-quality supportive cancer care and identifying specific processes and practice sites that should be targeted for quality improvement efforts. ${ }^{10,11}$ Such tools can help characterize care quality for patient populations served by a health care system as a whole, while revealing important variations at individual facilities within the system.

Quality indicators for supportive and end-of-life care have been successfully applied to electronic health record (EHR) data in research studies assessing care quality in patients with different cancer types and showing supportive care for cancer to be generally in need of quality improvement. ${ }^{10-15}$ In this paper, we examine supportive care findings from the first largescale application of quality indicators in a systemwide evaluation of lung cancer care in the Veterans Health Administration (VHA). The evaluation was part of a series of operationally motivated projects to identify targets for cancer care improvement in VHA. Lung cancer, the most common malignancy in the United States, accounts for one-fifth of all tumors diagnosed each year within this large, integrated health care system and is responsible for a significant proportion of the system's supportive care needs. Recently demonstrated benefits of early palliative care on the quality of life and end-of-life care in patients with advanced lung cancer point to the particular importance of assessing supportive care in this population. ${ }^{16}$ We report VHA evaluation findings and subsequent research analyses seeking to identify patient and facility characteristics associated with better quality supportive lung cancer care.

\section{Methods}

\section{Quality indicators}

Quality indicators for supportive cancer care were identified from a systematic review of existing measures and expert guidelines. A panel of 9 national palliative and supportive cancer care experts rated the validity and feasibility of the indicators for use in the VHA using a modified Delphi panel method adapted from the RANDUCLA appropriateness method ${ }^{17}$ and prioritized candidate indicators in a ranking exercise. Those with low validity or feasibility scores, or low priority rankings, were excluded, resulting in a final set of 12 quality indicators (8 supportive care, 4 end-of-life care) for use in the national evaluation.

\section{Evaluation population}

All incident non-small-cell (NSCLC) and small-cell (SCLC) lung cancer cases diagnosed within the VHA during $2007(\mathrm{~N}=7,816)$ were identified through the Veterans Affairs Central Cancer Registry (VACCR). Cases were eligible for the study if the patient had advanced cancer (extensive small-cell or metastatic non-small-cell lung cancer) and had lived long enough to be eligible for the supportive care that was being evaluated. Patients were excluded if the health record did not confirm the lung cancer diagnosis (eg, no pathologic diagnosis or diagnosis outside the VHA, $n=1,297$ ); they had a pre-existing or concurrent diagnosis of metastatic neoplasm other than lung cancer $(n=540)$; had died or enrolled in hospice $\leq 30$ days after diagnosis ( $\mathrm{n}=947)$; had documented "comfort measures only" $\leq 30$ days after diagnosis $(\mathrm{n}=91)$; had documented life expectancy of $\leq 6$ months at time of diagnosis $(n=39)$; or enrolled in a clinical trial (as care received as part of a trial may not be completely captured in the VHA record $(n=57)$. Of the patients meeting inclusion criteria, 2,969 were eligible for at least one of the supportive care quality indicators.

\section{Data collection}

EHRs were reviewed remotely by abstractors from the West Virginia Medical Institute, the VHA's contractor for its external peer-review program. Data were collected retrospectively from the year before to the 2007 diagnosis, with follow-up through 2009. Stage was determined through the VACCR or by abstraction if no VACCR stage was available. The VACCR also provided sociodemographic information including race, which is abstracted from patient charts by cancer registrars. Urban or rural residence was determined by using the rural-urban commuting area codes. Case-level quality indicator results were provided to each facility for review to identify any missed documentation, and abstractors updated data as appropriate. Facility characteristics for the Veterans Administration Medical Centers (VAMCs) at which patients received care were obtained from the 2009 Veterans Health Administration (VHA) Oncology Services Survey. ${ }^{18}$ The study was approved by the Veterans Administration Greater Los Angeles Healthcare System Institutional Review Board Subcommittee on Human Studies.

\section{Dependent variables}

For each quality indicator, cases eligible for the indicator were categorized as having received the specified care or not. Patient refusals of specified care or documentation of a contraindication were also considered to have met criteria for receipt of appropriate care. For bivariate and multivariate analyses, indicators were grouped into 4 domains: treatment toxicity (1 indicator), pain screening and management (6), palliative cancer treatment (4), and hospice (1). For these domain analyses, cases were considered to have met criteria for receipt of recommended supportive care if they received the care specified for all of the indicators for which they were eligible in the domain.

\section{Independent variables}

Patient characteristics included stage of disease, age, 
gender, race (white, black, other/unknown), marital status (married/living with partner, other), urban/rural residence, and performance status (poor/not poor), as shown in Table 1. Performance status was abstracted from the medical record as ECOG (Eastern Cooperative Oncology Group) or Karnofsky when present, but most of the time it was recorded in patients' charts qualitatively (eg, "poor performance status"). Cases were attributed to facilities based on the VACCR attribution, which is usually the VHA facility where treatment is initiated. Facility characteristics included geographic region; number of unique patients; facility complexity level; chemotherapy availability on-site; radiation therapy availability on-site; and types of palliative care services, psychosocial support, and patient tracking and case management available on-site (Table 2).

\section{Statistical analyses}

Bivariate analyses were performed to determine which patient and facility characteristics were associated with quality of care for treatment toxicity, pain, palliative treatment, and hospice. Multilevel logistic regression models were developed for each of these 4 domains to examine the relationship between indicator care receipt and patient and facility characteristics. Collinearity was assessed by examining Pearson correlations between independent variables, and highly collinear variables were not included in multivariate analyses.

Independent variables significantly associated with dependent variables in bivariate analyses or considered necessary for adjustment from conceptual standpoints were included in the multivariate models (cancer type [NSCLC or SCLC], age, sex, race, marital status, urban/rural classification, poor performance status, Veterans Integrated Service Network location, facility complexity level, facility region, as well as the facility having the following cancer-related services: tumor board, palliative care unit, palliative care services, chaplain, method for tracking patients through treatment and posttreatment care (to ensure receipt of timely and appropriate care), and presence of a case manager]. Testing yielded no significant interactions between any of the variables; thus interaction terms were not included in the final regressions. All analyses were performed using SAS statistical software, version 9.1 (Cary, NC).

\section{Results}

\section{Patient characteristics}

Table 1 summarizes patient characteristics of this elderly (mean age, 67 years; SD, 9), mostly white, and mostly male veteran cohort. In all, $15 \%$ of the cohort was black, nearly one-third lived in a rural area, and $46 \%$ were married or living with a partner. Eighteen percent had poor performance status, 38\% were referred for palliative care, and $81 \%$ died during the study period.

\begin{tabular}{|c|c|}
\hline Characteristic & $\begin{array}{c}\text { No. of } \\
\text { patients, } n(\%) \\
N=2,969\end{array}$ \\
\hline \multicolumn{2}{|l|}{ Lung cancer type } \\
\hline NSCLC & $2,518(85)$ \\
\hline $\mathrm{SCLC}$ & $451(15)$ \\
\hline \multicolumn{2}{|l|}{ Age, y } \\
\hline$<55$ & $238(8)$ \\
\hline $55-64$ & $1,213(41)$ \\
\hline $65-80$ & $1,194(40)$ \\
\hline$>80$ & $324(11)$ \\
\hline \multicolumn{2}{|l|}{ Gender } \\
\hline Male & $2,846(96)$ \\
\hline Female & $123(4)$ \\
\hline \multicolumn{2}{|l|}{ Race/ethnicity } \\
\hline White & $2,364(80)$ \\
\hline Black & $467(15)$ \\
\hline Other/unknown & $138(5)$ \\
\hline Married/living with partner & $1,362(46)$ \\
\hline \multicolumn{2}{|l|}{ Urban/rural residence } \\
\hline Urban & $2,083(71)$ \\
\hline Rural & $870(29)$ \\
\hline Poor performance status & $527(18)$ \\
\hline Referred for palliative care & $1,123(38)$ \\
\hline Death during study period & $2,410(81)$ \\
\hline
\end{tabular}

\section{Organizational characteristics}

Patients in the cohort were cared for at one or more of 111 VAMC facilities (Table 2), with the largest proportion (45\%) seen at facilities located in the South. Most patients (76\%) were seen in low-complexity facilities $(54 \%$ of facilities) and almost all (95\%) used a facility reporting having at least 1 tumor board ( $76 \%$ of facilities) in the 2009 VHA Oncology Services Survey. Most facilities (90\%) reported having chemotherapy on-site, with $99 \%$ of patients in our cohort receiving care at one of these facilities. Radiation therapy at most sites was provided by referral to a non-VA facility, although $31 \%$ of facilities had radiation therapy available on-site and these VAMCs provided care to $40 \%$ of the patients. A substantial proportion of facilities offered inpatient (91\%) and outpatient (76\%) palliative care consultation, serving the majority of patients, $95 \%$ and $78 \%$, respectively. Various forms of psychosocial support were reported at facilities serving over half of the study patients. Forty-five percent of veterans were seen at facilities 
TABLE 2 Facility characteristics and availability of oncology services

\begin{tabular}{|c|c|c|}
\hline Characteristic & $\begin{array}{l}\text { VAMCs, } \\
n(\%) \\
N=111^{a}\end{array}$ & $\begin{array}{l}\text { No. of patients, } \\
\begin{array}{c}n(\%) \\
N=2,969\end{array}\end{array}$ \\
\hline $\begin{array}{l}\text { Region in USb,19 } \\
\text { Midwest } \\
\text { Northeast } \\
\text { South } \\
\text { West }\end{array}$ & $\begin{array}{l}24(22) \\
19(17) \\
43(39) \\
25(23)\end{array}$ & $\begin{array}{r}668(23) \\
416(14) \\
1,342(45) \\
543(18)\end{array}$ \\
\hline $\begin{array}{l}\text { Number of unique patients } \\
<25,000 \\
25,000-50,000 \\
>50,000 \\
\text { No data }\end{array}$ & $\begin{array}{l}7(6) \\
39(35) \\
53(48) \\
12(11)\end{array}$ & $\begin{aligned} 61(2) \\
775(26) \\
2,095(71) \\
38(1)\end{aligned}$ \\
\hline $\begin{array}{l}\text { Complexity levelc } \\
\text { Low } \\
\text { Moderate } \\
\text { High } \\
\text { No data }\end{array}$ & $\begin{aligned} 60 & (54) \\
30 & (27) \\
9 & (8) \\
12 & (11)\end{aligned}$ & $\begin{array}{r}2,262(76) \\
565(19) \\
104(4) \\
38(1)\end{array}$ \\
\hline Has at least 1 tumor board & $94(85)$ & $2,806(95)$ \\
\hline Chemotherapy on site & $100(90)$ & $2,936(99)$ \\
\hline Radiation therapy on site & $34(31)$ & $1,200(40)$ \\
\hline $\begin{array}{l}\text { Palliative care services } \\
\text { Inpatient palliative care consultation } \\
\text { Inpatient palliative care unit } \\
\text { Outpatient palliative care consultation } \\
\text { Chaplain }\end{array}$ & $\begin{array}{l}101(91) \\
79(71) \\
84(76) \\
92(83)\end{array}$ & $\begin{array}{l}2,817(95) \\
2,203(74) \\
2,328(78) \\
2,496(84)\end{array}$ \\
\hline $\begin{array}{l}\text { Psychosocial support } \\
\text { Have a cancer patient support group } \\
\text { Psychologist specializing in cancer } \\
\text { Psychiatric NP or advanced practice RN }\end{array}$ & $\begin{array}{l}54(49) \\
25(23) \\
61(55)\end{array}$ & $\begin{array}{r}1,875(63) \\
896(30) \\
1,769(60)\end{array}$ \\
\hline $\begin{array}{l}\text { Tracking and case management } \\
\text { Any tracking of lung cancer patients } \\
\text { Midlevel practitioner (NP/PA) } \\
\text { responsible for tracking method } \\
\text { Case manager } \\
\text { Social worker specializing in cancer }\end{array}$ & $\begin{array}{l}15(14) \\
77(69) \\
50(45)\end{array}$ & $\begin{array}{r}1,334(45) \\
348(12) \\
2,020(68) \\
1,669(56)\end{array}$ \\
\hline
\end{tabular}

NP, nurse practitioner; PA, physician assistant; RN, registered nurse; VAMC, Veterans Administration Medical Center

Indicates facilities reporting indicated characteristics on the 2009 Veterans Health Administration (VHA) Oncology Services Survey. ${ }^{b}$ Represents US Census Bureau Regions ${ }^{19}$. 'Based on Fiscal Year 2008 Facility Complexity Level Model the VHA Office of Productivity, Efficiency, and Staffing using 7 complexity variables including patient population characteristics; level of intensive care unit; presence of complex clinical programs (eg, cardiac surgical program) numbers of resident slots, and research).

that provided care tracking for lung cancer patients $(41 \%$ of facilities) and at $14 \%$ of facilities (12\% of patients) the tracking method was monitored by a nurse practitioner or physician assistant. Sixty-eight percent of patients were cared for at facilities reporting the presence of a case manager (69\%). (The fact that a site has chemotherapy or any of the other aforementioned services in-house does not imply that patients receiving care at this site were eligible for or received these particular services, but rather that they were cared for at a facility reporting presence of the service.)

About $8 \%$ of patients were diagnosed at a VAMC dif- ferent from the VACCR attribution. Six percent received specialty service consultations or treatment at multiple VAMCs, and about $25 \%$ received at least one specialty service consultation or treatment at a non-VHA facility.

\section{Quality indicator eligibility and rates of receiving recommended care}

Patient eligibility for the quality indicators (Table 3) ranged from $1 \%$ (treatment of spinal cord compression) to $68 \%$ (prevention of chemotherapy-related nausea and vomiting). Few patients were eligible for palliative treatment indicators (palliative radiation therapy and treatment of spinal cord compression), with only $2 \%$ of patients (50 individuals) eligible for the imaging indicator. Eligibility for the two indicators related to use of short-acting opioids for breakthrough pain was also low (2\%-4\%).

Mean national rates for recommended supportive care were generally high (above $85 \%$ for 8 of the 12 indicators), ranging from $98 \%$ for outpatient pain screening to a low of $60 \%$ for spine MRI or myelography within 24 hours for suspected spinal cord compression (Table 3 ). There was pronounced variability across facilities, with facility rates in every domain ranging from 0\%-100\% (Figure 1). Many facilities scored $100 \%$ in at least 1 domain (eg, 44 of 109 facilities for pain screening; 51 of 94 for palliative cancer therapy). Eight (of 111) facilities did not provide recommended care in 1 domain and 1 did not provide recommended care in 2 domains (ie, $0 \%$ of recommended care).

In bivariate analyses (data not shown), referral to palliative care was associated with better care for treatment toxicity $(P=.04)$ but not the other domains. Patients with poor performance status were more likely to be referred to hospice ( $81 \%$ vs $74 \%$ for those with good performance status, $P=.005$ ) as were patients who lived in an urban zip code area ( $77 \%$ vs $71 \%$ for rural zip code, $P=.03$ ). In multivariate analyses (Table 4), small-cell cancer type, though not significant in the bivariate analyses, was associated with a higher odds of receiving recommended care [OR, $2.71 ; 95 \% \mathrm{CI}, 1.89-3.86)]$ in the treatment toxicity domain and lower odds in the pain domain [OR, 0.50; 95\% CI, $0.33-0.77)]$; and poor performance remained associated with higher odds of referral to hospice [OR, 1.49; 95\% CI, 1.12-1.99)] after adjusting for other patient and facility characteristics.

In multivariate analysis, moderate facility complexity was associated with lower quality in the toxicity domain than was low facility complexity [OR, 0.28; 95\% CI, 0.18$0.44)$ ]; however there was no such difference between the 


\section{Supportive/palliative care Qls by domain}

TABLE 3 Quality indicator eligibility and care receipt

\section{Treatment toxicity}

Prevention of

chemotherapy-related

nausea and vomiting

\section{Ql criteria}

Use of 2-drug regimen including a $5-\mathrm{HT}_{3}$ receptor antagonist or a neurokinin-1 receptor blocker AND dexamethasone immediately before chemotherapy with moderate or high acute emetic risk

\section{Pain}

Outpatient screening for pain in advanced cancer
Outpatient screening for presence or absence and intensity of pain using a quantitative scale in patients with stage IV/metastatic NSCLC or extensive stage SCLC
Reassessment after change in opioid treatment in advanced cancer
Assessment of effectiveness of new or modified opioid treatment in patients with stage IV/metastatic NSCLC or extensive stage SCLC
57

6,791

6,638

98

(1-245)

No. of

eligible

cohort

eligible

for Q

$N=2,969$
No. of

eligible

No. of

events with

careb $^{b}$

1,789

89

(range)

sho

Short-acting opioids for breakthrough pain in advanced cancer

\section{Short-acting opioid prescribed for} breakthrough pain at the same time long-acting opioid is prescribed in patients with stage IV/metastatic NSCLC or extensive stage SCLC

\section{Outpatient screening for pain prior to death or hospice

\begin{abstract}
Outpatient screening for the presence or absence and intensity of pain using a quantitative scale in patients with stage IV/metastatic NSCLC or extensive stage $\mathrm{SCLC} \leq 30$ days before death or hospice enrollment
\end{abstract}

\section{Reassessment after} change in opioid treatment prior to death or hospice

Short-acting opioids for breakthrough pain prior to death or hospice

\section{Assessment of the effectiveness of} new or modified opioid treatment in patients with stage IV/metastatic NSCLC or extensive stage SCLC $\leq$ 30 days before death or hospice enrollment
Short-acting opioid prescribed for breakthrough pain at the same time long-acting opioid is prescribed in patients with stage IV/metastatic NSCLC or extensive stage $\mathrm{SCLC} \leq$ 30 days before death or hospice enrollment (or documented reason why not)

\section{Palliative treatment} Radiation therapy for brain metastases
Whole-brain external beam radiation therapy or stereotactic radiosurgery for cranial metastasis in patients with stage IV/metastatic NSCLC or extensive stage $\mathrm{SCLC}$ $\begin{array}{llll}4 & 113 & 104 & 92\end{array}$

(1-9)

$\begin{array}{lllll}4 & 113 & 104 & 92 & \text { (1-9) }\end{array}$

25

1,340

1,238

92

$(1-44)$

r

.




\begin{tabular}{|c|c|c|c|c|c|c|}
\hline TABLE 3 continued from 365 & QI criteria & $\begin{array}{l}\% \text { of } \\
\text { cohort } \\
\text { eligible } \\
\text { for } Q \mathbf{l} \\
\mathbf{N}=\mathbf{2 , 9 6 9}\end{array}$ & $\begin{array}{l}\text { No. of } \\
\text { eligible } \\
\text { events }^{a}\end{array}$ & $\begin{array}{l}\text { No. of } \\
\text { eligible } \\
\text { events } \\
\text { with Ql } \\
\text { care }^{b}\end{array}$ & $\begin{array}{l}\text { National } \\
\text { rates of } \\
\text { Ql care, \% }\end{array}$ & $\begin{array}{l}\text { No. of eli- } \\
\text { gible events } \\
\text { per facility } \\
\text { (range) }\end{array}$ \\
\hline $\begin{array}{l}\text { Palliative treatment, cont. } \\
\text { Steroids for suspected spi- } \\
\text { nal cord compression }\end{array}$ & $\begin{array}{l}\text { Steroid treatment within } 24 \mathrm{~h} \text { for } \\
\text { newly suspected spinal cord com- } \\
\text { pression in patients with stage IV/ } \\
\text { metastatic NSCLC or extensive stage } \\
\text { SCLC }\end{array}$ & 1 & 34 & 25 & 74 & $(1-3)$ \\
\hline $\begin{array}{l}\text { Spine MRI or myelogra- } \\
\text { phy for suspected spinal } \\
\text { cord compression }\end{array}$ & $\begin{array}{l}\text { Spine MRI or myelography within } 24 \\
\mathrm{~h} \text { for suspected spinal cord com- } \\
\text { pression in patients with stage IV/ } \\
\text { metastatic NSCLC or extensive stage } \\
\text { SCLC }\end{array}$ & 2 & 50 & 30 & 60 & $(1-4)$ \\
\hline $\begin{array}{l}\text { Treatment for confirmed } \\
\text { spinal cord compression }\end{array}$ & $\begin{array}{l}\text { Radiotherapy or surgical decompres- } \\
\text { sion within } 24 \mathrm{~h} \text { for radiologically } \\
\text { confirmed spinal cord compression } \\
\text { in patients with stage IV/metastatic } \\
\text { NSCLC of extensive stage SCLC }\end{array}$ & 1 & 20 & 18 & 90 & $(1-2)$ \\
\hline $\begin{array}{l}\text { Hospice } \\
\text { Referral for palliative care } \\
\text { or hospice prior to death }\end{array}$ & $\begin{array}{l}\text { Referral to palliative care or hospice } \\
\geq 7 \text { says before death }\end{array}$ & 60 & 1,786 & 1,348 & 75 & $(1-64)$ \\
\hline
\end{tabular}

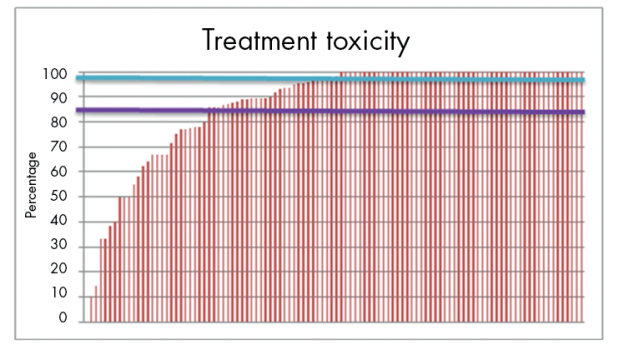

$N^{a}=106$

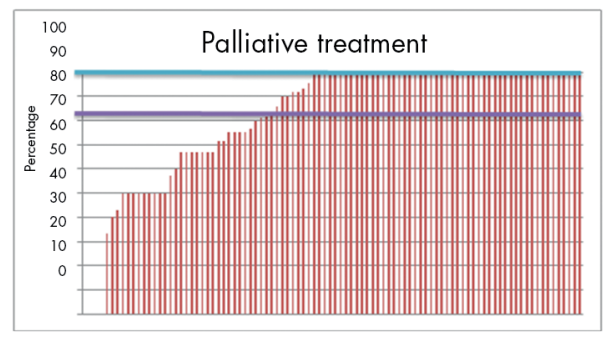

$N^{a}=94$
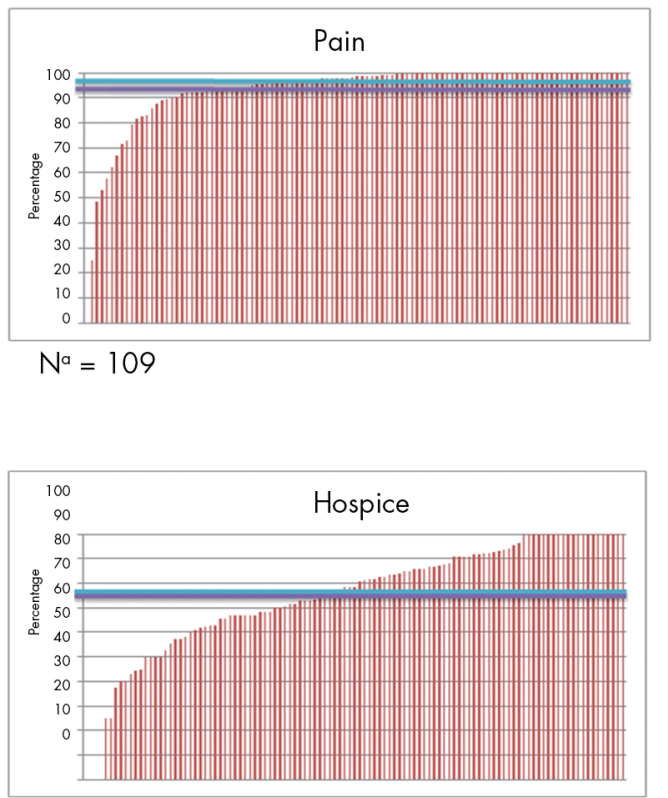

$N^{a}=109$

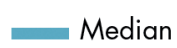

Mean

FIGURE 1 Quality indicator rate distributions by domain

${ }^{a} \mathrm{~N}=$ facilities with at least 1 eligible event; range $=0 \%-100 \%$ for all domains .

low- and high-complexity facilities. The presence of a patient tracking method appeared to be associated with better quality of care in the treatment toxicity domain [OR, 3.38; 95\% CI, 1.87-6.10)] and a higher likelihood of referral to hospice [OR, 1.60; 95\% CI, 1.22-2.28)] when the method was monitored by a midlevel practitioner (nurse practitioner or physician assistant), but no association was found for methods monitored by other types of staff. In the pain domain, having a psychologist specializing in cancer was associated with a higher odds of receiving recommended care [OR, 1.76; 95\% CI, 1.16-2.66)]. No patient or facility characteristics were associated with receiving recommended palliative cancer therapy, although statistical power was limited by the small numbers of eligible events. 


\section{Discussion}

Use of evidence-based measures to assess care quality proved feasible in this evaluation of supportive care for advanced lung cancer in a large national integrated health care system and confirmed that gaps found in smaller studies represent critical unmet needs for patients. The methods permitted individualized feedback to facilities, accompanied by support for quality improvement efforts. The effectiveness of providing facility feedback with quality improvement strategies will be evaluated in follow-up studies.

Although quality of supportive care as measured by this specific set of indicators was quite high compared to previous reports, ${ }^{10,13,15}$ substantial variation across facilities was observed even for measures with high overall performance. Comparatively high levels of supportive care may reflect greater emphasis on supportive measures for advanced lung cancer patients whose expectation of cure is low (other studies evaluated cohorts with mixed cancer types), or the fact that previous studies did not account for documentation of a reason for forgoing indicated care. Though high quality of supportive care for lung cancer in VHA nationally is encouraging, variability across individual facilities is of concern. Such variation may well exist in any large health care system, with patients potentially experiencing different standards of care depending on where they live.

In this study, facilities located in the South, treating 45\% of advanced lung cancer patients in the cohort, were associated with worse care in the treatment toxicity and hospice domains, and those in the Northeast appeared to generally have worse care for pain. Although reasons for these differences are unclear, geographic variation in Medicare hospice use has been related to a variety of determinants, ${ }^{20-23}$ some of which may also apply to VHA. Referral to palliative care or hospice was among the lowest scoring quality indicators in the evaluation, with a $75 \%$ national rate and $43 \%$ of facilities documenting referral for less than $75 \%$ of eligible cases. Although our measures determined only referral to palliative care or hospice (versus actual receipt of services), low rates may in part reflect provider anticipation of low local availability of hospice. Although the VHA Hospice and Palliative Care program has made progress in reducing variability in hospice access for Veterans, surveys conducted by Hospice-Veteran Partnerships showed lack of shared knowledge about the different systems of benefits and health care available for veterans, misunderstandings about referral processes among health care providers and payment for hospice services, and difficulties in caring for veterans across multiple care settings to be barriers to Veteran access to community services. ${ }^{24}$ Targeted inquiry at low-referral facilities may elucidate which of these and other possible challenges may suggest points of intervention for improvement in hospice referral patterns and support of appropriate hospice use.

Attempting to identify facility-related explanations for overall variability, we explored the potential role of a number of structural variables, including presence of a tumor board, a palliative care unit, outpatient palliative care services, chaplain services, presence of a cancer care tracking system, and presence of a case manager. Though facilities with a psychologist specializing in cancer provided better care for pain, and those with midlevel practitioners (nurse practitioner or physician assistant) monitoring patient 
tracking through care were more likely to appropriately refer to hospice and have better care for treatment toxicity, many facilities without such designated professionals also provided quality care in these domains. Because of limited methodological feasibility of demonstrating patient receipt of psychosocial/spiritual support and care tracking using medical record review, the final set of quality indicators did not include measures for these forms of care; however, psychosocial care is considered integral to supportive care in cancer $^{25}$ and care tracking has been associated with improved cancer care in non-VA settings. ${ }^{26}$ The presence of appropriate professionals providing cancer-specific psychological support and tracking may be directly associated with improved care, not only in the domains noted above, but also in the important domain of existential and emotional well-being not evaluated here. These services may also be part of larger facility-level quality improvement mechanisms contributing to cancer care quality that are worth identifying in future research. Lack of consistent explanations for the overall facility-level variation in this study suggests the need to identify data sources that can be used to measure additional organizational characteristics in future research.

Our study has several limitations. The scope of the national evaluation did not include indicators for all aspects of supportive care, including care for dyspnea, depression, and psychosocial distress; support for care givers; and care planning assistance. Small numbers of eligible events per facility for some indicators limit interpretation, particularly in the palliative treatment domain, where the largest range was 1-15 eligible events per facility. Facility characteristics used for analyses were identified from a survey and may be subject to respondent error. Potentially useful processes, such as a midlevel practitioner monitored tracking system were identified as "present" at the facility, but use for cohort patients was not possible to confirm, limiting direct linkage with better care. Some facility-level results may be influenced by errors in VACCR attribution to a facility that was not directly involved with the patient's care, specialty service receipt at multiple VAMCs, or through contract care at non-VHA facilities. Quality-of-care coordination between different VHA and non-VHA facilities for services not provided at the diagnosing facility, or to reduce travel burden if the VAMC was far from the patient's home may be associated with better or worse care quality and should be evaluated in future work.

In conclusion, use of quality indicators to evaluate quality of supportive lung cancer care in a large integrated health care system proved feasible, confirmed provision of overall high-quality supportive care, but identified a high degree of variability across individual facilities in the system. Facility characteristics examined did not explain this variation; however, the data suggested that, while not account- ing for the overall variation, having professionals providing cancer-specific psychological support and care-tracking may contribute to better quality of care in some domains. Difficulties in identifying predictors of quality suggest that future research should include qualitative comparisons of facilities with varying rates of providing recommended supportive care to identify potentially impactful organizational factors not examined in this study.

\section{References}

1. Lorenz KA, Dy SM, Naeim A, et al. Quality measures for supportive cancer care: the Cancer Quality-ASSIST Project. J Pain Symptom Manage. 2009;37:943-964.

2. Dy SM, Asch SM, Naeim A, Sanati H, Walling A, Lorenz KA. Evidence-based standards for cancer pain management. J Clin Oncol. 2008;26:3879-3885

3. Gordon, DB, Dahl, JL, Miakowski, C. American Pain Society recommendations for improving the quality of acute and cancer pain management. Arch Intern Med. 2005;165:1574-1580.

4. Lorenz, KA, Lynn, J, Dy, SM, et al. Evidence for improving palliative care at the end of life: A systematic review. Ann Intern Med. 2008;148:147-159.

5. Seow, H, Snyder, CF, Shugarman, LR, et al. Developing quality indicators for cancer end-of-life care: Proceedings from a national symposium. Cancer. 2009;115:3820-3829.

6. Lorenz KA, Lynn J, Dy SM, et al. Agency for Healthcare Research and Quality (US). Cancer care quality measures: symptoms and endof-life care. http://www.ncbi.nlm.nih.gov/books/NBK38028/. Published 2006. Accessed December 17, 2012.

7. Lorenz KA, Lynn J, Dy S, et al. Quality measures for symptoms and advance care planning in cancer: A systematic review. J Clin Oncol. 2006;24:4933-4938.

8. Lorenz KA, Rosenfeld K, Wenger N. Quality indicators for palliative and end-of-life care in vulnerable elders. JAGS. 2007;55(s2):S318S326.

9. Dy SM, Lorenz KA, O'Neill SM, et al. Cancer Quality-ASSIST supportive oncology quality indicator set. Cancer. 2010;116:32673275.

10. Jacobson JO, Neuss MN, McNiff KK, et al. Improvement in oncology practice performance through voluntary participation in the Quality Oncology Practice Initiative. J Clin Oncol. 2008;26:18931898.

11. Jacobsen PB, Shibata D, Siegel E, et al. Evaluating the quality of psychosocial care in outpatient medical oncology settings using performance indicators. Psycho-oncology. 2010; 20:1221-1227.

12. Walling AM, Asch SM, Lorenz KA, et al. The quality of care provided to hospitalized patients at the end of life. Arch Intern Med. 2010;170:1057-1063.

13. Dy SM, Asch SM, Lorenz KA, et al. Quality of end-of-life care for patients with advanced cancer in an academic medical center. J Palliat Med. 2011;14:451-457.

14. Gonsalves WI, Tsewang T, Krishnamurthy J, et al. Effect of palliative care services on the aggressiveness of end-of-life care in the Veteran's Affairs cancer population. J Palliat Med. 2011;14:1231-1235.

15. Malin JL, O’Neill SM, Asch SM, et al. Quality of supportive care for patients with advanced cancer in a VA medical center. J Palliat Med. 2011;14:573-577.

16. Temel JS, Greer JA, Admane S, et al. Longitudinal perceptions of prognosis and goals of therapy in patients with metastatic non-smallcell lung cancer: results of a randomized study of early palliative care. J Clin Oncol. 2011;29:2319-26.

17. Brook RH, Chassin MR, Fink A, Solomon DH, Kosecoff J, Park RE. A method for the detailed assessment of the appropriateness of medical technologies. Int J Technol Assess Health Care. 1986;2:53-63.

18. Department of Veterans Affairs, Veterans Health Administration, Office of the Assistant Deputy Under Secretary for Health for Policy and Planning. 2009 VHA Oncology Services Survey. April, 2010. Accessed November 1, 2010 
19. US Census Bureau. Census Bureau regions and divisions with state FIPS codes. Available from URL: https://www.census.gov/geo/ maps-data/maps/pdfs/reference/us_regdiv.pdf. Accessed December 17, 2012.

20. Virnig BA. Toward a better understanding of the role of geography in intensity of end-of-life care: Must we first come to an understanding of end-of-life care? Medical Care. 2007;45:374-376.

21. Virnig BA, Kind S, McBean M, Fisher E. Geographic variation in hospice use prior to death. JAGS. 2000;48:117-11.

22. McCarthy EP, Burns RB, Davis RB, Phillips RS. Barriers to hospice care among older patients dying with lung and colorectal cancer.J Clin Oncol. 2003;21:728-735.

23. Virnig BA, Ma H, Hartman LK, Moscovice I, Carlin B. Access to home-based hospice care for rural populations: identification of areas lacking service. J Palliat Med. 2006;9:1292-1299.

24. Jones D, Edes T, Shreve S. You won't know if you're improving unless you measure: Recommendations for evaluating hospice-veteran partnerships. J Pain Symptom Manage. 2006;32:488-496.

25. Surbone A, Baider L, Weitzman TS, Brames MJ, Rittenberg CN, Johnson J, et al. Psychosocial care for patients and their families is integral to supportive care in cancer: MASCC position statement. Support Care Cancer. 2010;18:255-263.

26. Callahan M, Sanderson, J. A breast cancer tracking system. The Permanente Journal. 2000;4:36-39. http://www.thepermanentejournal. org/files/Fall2000/BreastCancer.pdf. Accessed June 1, 2012. 